Article

\title{
An Exponentially Distributed Stochastic Model for Sustainability Measurement of a Healthcare System
}

\author{
Faramarz Khosravi ${ }^{1, *}$, Gokhan Izbirak ${ }^{1}$ and Kehinde Adewale Adesina ${ }^{2} \mathbb{0}$ \\ 1 Department of Industrial Engineering, Eastern Mediterranean University, Famagusta 99628, Cyprus; \\ gokhan.izbirak@emu.edu.tr \\ 2 Department of Food Engineering, Near East University, Nicosia 99138, Cyprus; kehinde.adesina@neu.edu.tr \\ * Correspondence: Faramarz.khosravi@emu.edu.tr
}

Received: 24 January 2018; Accepted: 18 February 2019; Published: 1 March 2019

\begin{abstract}
As the global environment is getting more competitive, sustainability is increasingly becoming an important assessment tool. An exponential distribution stochastic model is developed for the purpose of assessing and measuring the sustainability of healthcare system. The aim of this study is to provide a sustainability measuring model that is driven by the actual distribution status of the sustainability indicators. In this paper, the notions of the "Triple Bottom Line" (TBL) are followed in deriving the sustainability challenge and capacity indicators for the environmental, social, and economic indicators. Since basic challenges and capacities depend on the modes of the organization, the study proposes an exponentially distributed stochastic model for measuring sustainability. A numerical illustration of Iranian healthcare is presented to demonstrate the efficiency of the proposed model. In the results obtained, sustainability index for environmental, economic, and social are $54.40 \%, 48.80 \%$, and $66.80 \%$ respectively. It indicates the healthcare achieved some sustainability through the social aspect; therefore, improving the environmental and economic aspect of the TBL is necessary. The proposed model can be used as a panoramic tool for effective measurement of the sustainability level of any healthcare system.
\end{abstract}

Keywords: Healthcare Sustainability; Triple Bottom Line; Exponentially distributed indicators; Performance measurement

\section{Introduction}

The concepts of sustainability have gained wider applications within concerted efforts geared toward maintaining the balance between the depletion of resources in such a way that the coming generations can benefit from the resources. Sustainability is a developmental strategy necessary for meeting the needs of the present users without jeopardizing the opportunity of future generations to meet their needs [1]. Many studies have been conducted on how to assess, appraise, and evaluate the sustainability of corporations by combining the economic, social, and environmental aspects of human life [2-5]. As it stands today, top managers and researchers are duty-bound to constantly appraise, assess, and evaluate their corporate's sustainability performance. Most times, constant re-appraisal of the sustainability scores would better reposition the corporation strategically so as to contribute immensely and meaningfully to the environmental and social issues of their hosts [6]. The concept of sustainability can also serve as a means of measuring the performance of a country [6,7]. It may be recalled that sustainability involves finding balance between the depletion and conservation of resources. It is the level of the resources (natural, environment, and capital) the previous generation is bequeathing to the coming generations; however, losses in some natural resources are enviable [8]. Some researchers have argued on the belief that losses in the natural resources can be compensated for through increased capital. Others maintained the belief that capital cannot be substituted for resources. In this regard, 
therefore, two major views have surfaced in defense of sustainability as follows: (i) stock wealth to be inherited by the coming generation cannot be less than the amount inherited by previous generation, and (ii) stock of environmental assets bequeathed to the coming generation must be the same proportion inherited by the previous generation $[9,10]$. This is the basic concept of weak and strong sustainability, respectively [11]. It has been reported that it is possible to make a choice between weak sustainability (WS) and strong sustainability (SS) [12]. The four dimensions for finding WS and SS are given as: (i) physical flows of materials, (ii) environmental protection expenditure, (iii) physical and monetary accounting of environmental assets, and lastly (iv) environmentally modified macro-aggregates. These categories are germane for the measurement of WS and SS [13]. Subsequent reports pointed out that the major difference between weak and strong sustainability is the extent at which sustainability between different forms of capital is evaluated [13-15].

Sequel to the aforesaid, it is necessary to bear in mind that sustainability assessments often rely on different kinds of indicators which are measured in units pertinent to the particular metric. More so, the same unit of measurement makes the identification and comparison of indicators much more achievable. These indicators can be synthesized analytically, statistically, or graphically [16,17]. The perspective of an embedded system developed to conceptualize Canada's healthcare sustainability for novel and productivity solutions for measuring sustainability was found to minimize risk with the health of the populace being optimized [18]. Hence, to achieve sustainable development, appropriate policies must be strictly followed in arriving at some of these requirements for defining, measuring, designing, and evaluating the objectives. A digital tool adapted for promoting various engagements among the stakeholders in healthcare systems toward attaining sustainability through an online health digital showed that social sustainability of the healthcare was greatly influenced by the online engagement platform [19]. This study seeks to provide a quantitative assessing methodology which would give insight into the integration of multi-criteria techniques into a procedure for the assessment of the sustainability index of a hospital.

Many assessment methods have been proposed and applied. For the promotion and development of sustainable goals in a healthcare system, various emerging algorithms and machine learning techniques have been identified for assessing the sustainability of smart healthcare system for disease diagnosis [20]. The method proposed in Reference [21] only aimed at assessing the degree of sustainability in all dimensions except for those leading to environmental sustainability index and well-being assessment. The appropriate indicators for assessing sustainability are often based on the multidisciplinary nature of the organization, which usually form a basis for quantitative decision making [22]. Some of the newest assessment methods for healthcare sustainability include the Leadership in Energy and Environmental Design (LEED), Building Research Establishment Environmental Assessment Methodology (BREEAM), Comprehensive Assessment System for Built Environment Efficiency (CASBEE), Deutsche Gesellschaft fur Nachhaltiges Bauen (DGNB), Haute Quality Environmental (HQETM), Sustainable Building Tool (SBTool) [23], and Healthcare Building Sustainability Assessment (HBSA) [24].

It is worthy to note that these tools mentioned were used to ascertain the sustainability of the healthcare system based on buildings and other infrastructures. Those tools in Reference [22] used the environmental impact assessment of buildings, infrastructures, and construction work to measure sustainability. Similarly, HBSA was used to measure the environmental impact of healthcare buildings and assessed healthcare sustainability through a set of benchmarks within the life-cycle efficiency of healthcare buildings and other infrastructures. The benchmarks were defined as the rate of resource depletion, waste generation, overhead costs, and operational environmental impacts of the healthcare buildings. A new sustainability tool for measuring sustainability, Sustainable High-Quality Healthcare (SUST Health) has been widely studied and implemented $[25,26]$. In summary, SUST Health is based on the submission of the criteria and indicators to scrutiny by a group of experts through specified questionnaires. This group is comprised of selected experts who have been trained to identify and assign relative weight to the indicators and the use of weighing model such as Analytic Network 
Process (ANP). Invariably, SUST Health is structured and applicable to standardized situations in the healthcare system and has been recognized internationally for aligning either directly or indirectly to sustainable development initiatives.

A similar perspective for developing indicators for the sustainability criteria through Specific, Measurable, Assignable, Realistic, and Time-based (SMART) has been applied [27]. The selection of sustainability factors for a particular healthcare system must satisfy some conditions, such as: (i) must be homogeneous, (ii) non-dimensional, and (iii) with the tendency to possess equal weight. In addition to these conditions, the indicators must equally be related to sustainability TBL issues surrounding the particular healthcare system. A very important attribute is the reduction of assumptions for the selection of indicators; choice of any indicators is based and justified by appropriate and realistic rationales, fathomable within the prevailing dynamics of the system. This should not be confused with "smart city healthcare system". The "smart city" attached to the healthcare was merely used to describe a healthcare system where artificial intelligence, big data, decision making, information and communication technology (ICT), and the internet-of-things (IoT) are the hallmark [20]. Furthermore, a smart city would possess the ability to tap various information and communication technology (ICT) techniques available to find solution to some sundry problems in governance, environment, economy, healthcare, and the society at large. It must also have the propensity to enhance the quality of life of everyone living therein and should be capable of adapting computational intelligence through appropriate mathematical models to deal with real-life problems [28].

Another similar smart health study was conducted on knowledge management in healthcare sustainability of traditional Chinese diets. A knowledge graph was designed to incorporate healthy diet information on the internet with a semantic retrieval system. This system aided learning and tilted the populace toward having a balanced diet [29]. This study adapted SMART due to the fact that it allows sustainability analysis to be based on the prevailing situations in a particular healthcare system irrespective of their former sustainability status. Mainly, it attempts to leverage on some of the protocols, especially the aspect of utilizing verified indicators. The study advocates the utilization of the prevailing sustainability indicators in a particular healthcare system to determine the sustainability index of that particular healthcare system. The effort now is focused on the utilization of the real statistical distribution of the identified indicators for the analysis. The study proposes an exponential distribution model for measuring the sustainability index of a healthcare system. Unlike the previous methods, where the dimension of the indicators was used, functionality and adequacy of these indicators are employed for this study. Moreover, the focus of this study traverses beyond the healthcare buildings and other construction works. It holistically considers the sustainability of a healthcare system as a way of evaluating the perceptions of the users (patients), medical personnel, infrastructure, and other stakeholders.

Sustainability and sustainable development procedures have been given high priority by most scientists, government, industry, and even the public through to the wide application of the TBL indicators of social, environmental, and economic [29-38]. However, little literature is available on how to measure the sustainability of healthcare systems using the actual statistical distribution of the data. For a system to reach its sustainability index, there must be a decrease in the challenge factor and an increase in the capacity factor. In other words, the challenge must not exceed capacity. For measuring sustainability, both capacity and challenge indicators are random variables implying that their respective cumulative density function can be used [39]. By assuming a normal distribution for both capacity and challenge factors, taking $\mu_{c}, \mu_{h}$ as the mean of capacity and challenge factors respectively, $\sigma_{c}^{2}, \sigma_{h}^{2}$ are the respective variance of capacity and challenge factors, $\varphi$ is the probability that one normal standard random variable $(Z)$ will be smaller than one specific value $(z)$ of that variable, and sustainability can be expressed as Equation (1)

$$
\text { Sus }=\varphi\left(\frac{\mu_{\mathrm{c}}-\mu_{\mathrm{h}}}{\left(\sigma_{\mathrm{c}}^{2}+\sigma_{\mathrm{h}}^{2}\right)^{1 / 2}}\right)
$$


However, sustainability assessment has been evaluated based other statistical distributions, either in discrete or continuous mode. These statistical distributions include binomial, Poisson, geometric, negative binomial, exponential, uniform, normal, log-normal, and gamma. Among these distributions, exponential distribution is of interest to this study due to its many advantages. Some of these unique advantages include: (i) existing within the continuous probability distribution domain with constant failure rate (lambda) suitable for analyzing real-life situations, and (ii) possessing a constant response time and forming a veritable tool for predicting the mean time of the variables.

The study aims to examine an exponential distribution approach for measuring the sustainability of a service-oriented organization over time from their exponentially distributed indicators. We anticipate contributing to the existing literature as follows: (i) measuring the appropriate and adequate sustainability value of the healthcare system that is based on the actual statistical distribution of its sustainability factors, (ii) providing a panoramic tool for appraising, assessing, and measuring the sustainability effectiveness of any other organizations with exponentially distributed indicators, (iii) providing leverage for comparing the sustainability issues of different companies functioning in the same or related sector, possessing the same indicators that are measured in the unit, and (iv) within known literature, there are little or no studies on the measurement of the sustainability value of organization using the actual statistical distribution of the indicators. Previous studies [24] were based on the basic assumption of the normal distribution; hence, this study will empirically adopt and validate an exponential distributed probabilistic approach for sustainability measurement. After the introduction presented in Section 1, the remainder of this article is structured as follows. Section 2 presents the materials and methods, where the proposed exponentially distributed sustainability model and the validation are explained. Section 3 presents the numerical illustration of the model, while results and discussions are presented in Section 4. Section 5 concludes the article.

\section{Methods, Theoretical Considerations and Model Development}

\subsection{The Proposed Exponentially Distributed Sustainability Model}

Sustainability is the probability of challenge is less than the healthcare system's capacity. Therefore, Equation (2) is used to express sustainability as follows:

$$
\text { Sus }=\mathrm{P}(\mathrm{H}<\mathrm{C})=\mathrm{P}(\mathrm{H}-\mathrm{C}<0)
$$

where Sus is the sustainability of the healthcare system, $\mathrm{H}$ is the challenge factor, and $\mathrm{C}$ is the capacity factor of the company. Assuming that factors of capacity and challenge are exponentially distributed, then from Equation 2. probability density function can be modeled as in Equations (3) and (4);

$$
\begin{aligned}
& f\left(h, \lambda_{1}\right)=\frac{1}{\lambda_{1}} e^{\frac{-h}{\lambda_{1}}} \\
& f\left(c, \lambda_{2}\right)=\frac{1}{\lambda_{2}} e^{\frac{-c}{\lambda_{2}}}
\end{aligned}
$$

Let $\mathrm{Y}=\mathrm{H}-\mathrm{C}$

Thus, Equation (5) the Cumulative Density Function (CDF) of $Y, F_{Y}(y)$ is piecewise, when $y \leq$ 0 or $\mathrm{y} \geq 0$. 
Case (i) $y \leq 0$;

$$
\begin{aligned}
\mathrm{F}_{\mathrm{Y}}(\mathrm{y})=\mathrm{P}(\mathrm{Y} \leq \mathrm{y}) & =\mathrm{P}((\mathrm{H}-\mathrm{C}) \leq \mathrm{y})=\mathrm{P}(\mathrm{C} \geq \mathrm{H}-\mathrm{y})=\int_{0}^{\infty} \int_{\mathrm{h}-\mathrm{y}}^{\infty} \mathrm{f}_{\mathrm{H}, \mathrm{C}}(\mathrm{h}, \mathrm{c}) \mathrm{d}_{\mathrm{c}} \mathrm{fdh} \\
& =\int_{0}^{\infty} \int_{\mathrm{h}-\mathrm{y}}^{\infty}\left(\lambda_{1} \mathrm{e}^{-\lambda_{1} \mathrm{~h}}\right)\left(\lambda_{2} \mathrm{e}^{-\lambda_{2} \mathrm{c}}\right) \mathrm{dcdh}=\int_{0}^{\infty} \lambda_{1} \mathrm{e}^{-\lambda_{1} \mathrm{~h}}\left(\mathrm{e}^{-\lambda_{2}(\mathrm{~h}-\mathrm{y})} \mid \begin{array}{c}
\infty \\
\mathrm{h}-\mathrm{y}
\end{array}\right) \mathrm{dh} \\
& =\int_{0}^{\infty} \lambda_{1} \mathrm{e}^{\lambda_{2} \mathrm{y}} \mathrm{e}^{-\left(\lambda_{1}+\lambda_{2}\right) \mathrm{h}} \mathrm{dh}=\lambda_{1} \mathrm{e}^{\lambda_{2} \mathrm{y}}\left(-\frac{1}{\lambda_{1}+\lambda_{2}} \mathrm{e}^{-\left(\lambda_{1}+\lambda_{2}\right) \mathrm{h}} \mid \begin{array}{c}
\infty \\
0
\end{array}\right) \\
& =\frac{\lambda_{1} \mathrm{e}^{\lambda_{2} \mathrm{y}}}{\lambda_{1}+\lambda_{2}}
\end{aligned}
$$

Case (ii) y $>0$; the Cumulative Density Function (CDF) can also be expressed in Equation (6),

$$
\begin{aligned}
\mathrm{F}_{\mathrm{Y}}(\mathrm{y})=\mathrm{P}(\mathrm{Y} \leq \mathrm{y}) & =1-\mathrm{P}(\mathrm{Y}>\mathrm{y})=1-\mathrm{P}((\mathrm{H}-\mathrm{C})>\mathrm{y})=1-\mathrm{P}(\mathrm{C}<\mathrm{H}-\mathrm{y}) \\
& =1-\int_{\mathrm{y}}^{\infty} \int_{0}^{\mathrm{h}-\mathrm{y}} \mathrm{f}_{\mathrm{H}, \mathrm{C}}(\mathrm{h}, \mathrm{c}) \mathrm{dcdh}=1-\int_{\mathrm{y}}^{\infty} \int_{0}^{\mathrm{h}-\mathrm{y}}\left(\lambda_{1} \mathrm{e}^{-\lambda_{1} \mathrm{~h}}\right)\left(\lambda_{2} \mathrm{e}^{-\lambda_{2} \mathrm{c}}\right) \mathrm{dcdh} \\
& =1-\int_{\mathrm{y}}^{\infty}\left(\lambda_{1} \mathrm{e}^{-\lambda_{1} \mathrm{~h}}\right)\left(1-\mathrm{e}^{\lambda_{2} \mathrm{c}} \mid \begin{array}{c}
\mathrm{h}-\mathrm{y} \\
0
\end{array}\right) \\
& =1-\int_{0}^{\infty}\left(\lambda_{1} \mathrm{e}^{-\lambda_{1} \mathrm{~h}}\right)\left(1-\mathrm{e}^{-\lambda_{2}(\mathrm{~h}-\mathrm{y})}\right) \mathrm{dh} \\
& =1-\left(\lambda_{1} \mathrm{e}^{-\lambda_{1} \mathrm{~h}}-\frac{\lambda_{1}}{\lambda_{1}+\lambda_{2}} \mathrm{e}^{-\left(\lambda_{1}+\lambda_{2}\right) \mathrm{h}+\lambda_{2} \mathrm{y}}\right) \mathrm{dh} \\
& =1-\left.\left(-\mathrm{e}^{-\lambda_{1} \mathrm{~h}}-\frac{\lambda_{1}}{\lambda_{1}+\lambda_{2}} \mathrm{e}^{-\left(\lambda_{1}+\lambda_{2}\right) \mathrm{h}+\lambda_{2} \mathrm{y}}\right)\right|_{\infty} ^{\infty} \\
& =1-\left(-\mathrm{e}^{-\lambda_{1} \mathrm{y}}+\frac{\lambda_{1}}{\lambda_{1}+\lambda_{2}} \mathrm{e}^{-\lambda_{1} \mathrm{y}}\right)=1-\frac{\lambda_{2} \mathrm{e}^{-\lambda_{1} \mathrm{y}}}{\lambda_{1}+\lambda_{2}}
\end{aligned}
$$

Exponential random variable involves the time of an event and time between two events. In the case of time of an event, sustainability is measured based on "challenge cannot surpass capacity" given in Equation (5). Similarly, for the second case, time between two events, sustainability is profiled on "capacity cannot surpass challenge", also given in Equation (6) For instance, for the first case time of an event, if the capacity is defined as time of staff training, then the increase in time spent (hours or days of the training) for the training must increase. In this instance, Equation (5) is employed to determine the sustainability. Similarly, for the second case, time between two events, if challenge is defined as time between two complaints, then the decrease in time interval at which at least two complaints are reported must decrease (lower rate of complaint). In this situation, Equation (6) is used to measure the sustainability of the system. For this present work, the indicators are measured as the time the particular event took place. Hence, Equation (5) is employed to measure the sustainability of the healthcare system. Wherever indicators with time between two events are encountered, the condition of such an indicator is reversed and Eq. 5 is applied to calculate its sustainability.

By differentiating Equations (5) and (6) with respect to y, Equation (7) is obtained as;

$$
f_{Y}(y)= \begin{cases}\frac{\lambda_{1} \lambda_{2}}{\lambda_{1}+\lambda_{2}} e^{\lambda_{2} y} & y \leq 0 \\ \frac{\lambda_{1} \lambda_{2}}{\lambda_{1}+\lambda_{2}} e^{-\lambda_{1} y} & y>0\end{cases}
$$

Equation (8) is the probability density function with parameters $\lambda_{1}$ and $\lambda_{2}$

$$
\text { sus }=P(H \leq C)=P(H-C \leq 0)=P(Y \leq 0)=\int_{-\infty}^{0} \frac{\lambda_{1} \lambda_{2}}{\lambda_{1}+\lambda_{2}} e^{\lambda_{2} y} d y
$$


The parameters for determining the exponential distribution are estimated from the number of observations n using Equations (9)-(15) as follows;

$$
\begin{gathered}
\text { Number of Interval, } \mathrm{k}=\sqrt{\mathrm{n}} \\
\text { Range }=\text { Maximum }_{\text {value }}-\text { Minimum }_{\text {value }} \\
\text { Class interval }=\frac{R}{\sqrt{n}} \\
\text { Mean value } \overline{\mathrm{x}}=\frac{\sum_{\mathrm{i}=1}^{\mathrm{k}} \mathrm{x}_{\mathrm{i}} \mathrm{f}_{\mathrm{i}}}{\sum_{\mathrm{i}=1}^{\mathrm{k}} \mathrm{f}_{\mathrm{i}}} \\
\text { Parameter of exponential distribution, } \lambda=\frac{1}{\overline{\mathrm{x}}}
\end{gathered}
$$

Probability density function of exponential distribution, $f(X=x)=\lambda e^{-\lambda x}$

Therefore, expected frequency $o_{i}$ for ith interval $=\mathrm{n} \int_{\text {lower bound }}^{\text {upper bound }} \frac{1}{\overline{\mathrm{x}}} \mathrm{e}^{\left(\frac{-\mathrm{x}}{\mathrm{x}}\right)} \mathrm{dx}$

\subsection{Exponential Distribution Validation (Hypothesis Testing Procedure)}

A well-defined problem is characterized by detailed conditions of its relationship with various terms. Most often, such a detailed and structured problem is not readily defined, therefore, in such cases the assumption of some terms is necessary whenever a solution is anticipated. An explicit assumption, where other experts can ask questions and also contribute comments, is always preferred. This study assumed that both challenge and capacity factors are exponentially distributed. To check the validity of this assumption, Chi-Squared goodness of fit test is adopted. The process of checking and validating has been summarized in five steps [40]:

Step 1: State the null $H_{0}$, and alternative $H_{1}$, hypothesis

Step 2: Choose an appropriate value of the level of significance, $\alpha$ (standard value for $\alpha=0.05$ ) Step 3: In Equation (16), the appropriate statistic:

$$
\chi^{2}=\sum_{i=1}^{k} \frac{\left(o_{i}-e_{i}\right)^{2}}{e_{I}}
$$

Calculate the statistic and show the critical region

Step 4: Reject $H_{0}$ if the value of the statistic is in the critical region otherwise fail to reject $H_{0}$ Step 5: Draw the conclusion

Hence,

$$
\begin{gathered}
H_{0}=\text { distribution of the value of the indicator is exponential } \\
H_{1}=\text { distribution of the value of the indicator is not exponential }
\end{gathered}
$$

\section{Numerical Illustration}

A numerical illustration of the proposed model is conducted using the TBL indicators of the General Hospital in Tehran. The hospital is the biggest Government hospital located within the heart of the over 10,000,000 populated capital city of Iran. The hospital is organized into various wards, namely male, female, accident and emergency, surgical, children, and maternity. The male and female ward can accommodate 60 patients each, maternity 30 patients, surgical ward 20 patients, children's ward 80, and accident and emergency only 15 patients. The challenge and capacity criteria based on the triple bottom line adapted from the SUST health tool [26] are presented in Table 1. Similarly, challenge and capacity indicators with the rationales determined according to SMART logic [27] are presented in Tables $2-4$. For this case study, the indicators were measured in a unit of time; therefore, 
the ability to achieve a specific factor in less time determines the capacity of the hospital and those factors that are achieved in more time constitute the challenge factors. Various data collated for the estimation of these results have been attached as a supplementary file in MS Excel format. Working hours is adopted as the unit of measurement.

Table 1. Hospital sustainability evaluation criteria for the existing operative hospital studied adapted from sustainable healthcare evaluation tool (SUST Health tools).

\begin{tabular}{|c|c|c|}
\hline Macro-Area & Criteria & Indicators \\
\hline \multirow{7}{*}{$\begin{array}{l}\text { Economic } \\
\text { Sustainability }\end{array}$} & \multirow[b]{2}{*}{ Clinical Performance } & Hospital Acquired Infections \\
\hline & & Health technology management \\
\hline & \multirow{2}{*}{ Managerial Performance } & Build quality \\
\hline & & Staff Qualification and Education \\
\hline & \multirow{3}{*}{ Technological Performance } & ICT (information and communication \\
\hline & & technology) \\
\hline & & Biomedical Technologies Obsolescence \\
\hline & Envelope Technologies & Maintenance Technologies \\
\hline \multirow{11}{*}{$\begin{array}{l}\text { Environmental } \\
\text { Sustainability }\end{array}$} & Materials and Resources & $\mathrm{Km} 0$ \\
\hline & Saving with Efficiency & Recycled Components \\
\hline & \multirow{2}{*}{ Urban Planning } & Transportation \\
\hline & & Risks \\
\hline & \multirow{3}{*}{ Unconventional Source Supply } & Electricity \\
\hline & & Heating and Cooling \\
\hline & & Domestic Hot Water \\
\hline & \multirow[t]{2}{*}{ Waste Care } & Hazardous Waste \\
\hline & & Waste generation \\
\hline & \multirow[t]{2}{*}{ Water Care } & Water Consumption \\
\hline & & Water Recycling \\
\hline \multirow{6}{*}{ Social Sustainability } & \multirow{2}{*}{ Comfort } & Lighting \\
\hline & & Indoor Air Quality \\
\hline & \multirow{2}{*}{ Distribution } & Space flexibility \\
\hline & & Accesses and Paths \\
\hline & \multirow{2}{*}{ Humanization } & Safety and Security \\
\hline & & Health Promotions \\
\hline
\end{tabular}

Source: [38].

Having strictly adhered to the conventional guidelines provided by SUST Health as given in Tables 1-4 presents the sustainability indicators (challenge and capacity) for the TBL with their rationales coined according to SMART and based on the prevailing situations at the healthcare system. 
Table 2. Identified Economic indicators and rationales for the Triple Bottom Line (TBL) of the Iranian General hospital determined according to SMART logic.

\begin{tabular}{|c|c|}
\hline Sustainability Criteria & \multirow{3}{*}{ Rationale } \\
\hline Economic Sustainability & \\
\hline Capacity & \\
\hline $\begin{array}{l}\text { The average time interval between diagnosis and procurement of prescribed medications } \\
\text { prior to treatment by the patient. }\end{array}$ & $\begin{array}{l}\text { Temporary pause in the treatment due to the waiting time between purchasing and dispensing of } \\
\text { classified drugs or related medications. }\end{array}$ \\
\hline $\begin{array}{l}\text { The hospital has the capacity to re-strategize in a timely way to reorganize health } \\
\text { personnel to brief-up the shortages of personnel in case of industrial action. } \\
\text { Average time to take the vital signs of an in-patient. }\end{array}$ & $\begin{array}{l}\text { The society is prone to infection or communicable diseases. Timely intervention on the part of the } \\
\text { healthcare practitioners in term of their ability to respond swiftly is sacrosanct. } \\
\text { This is an indication of normalcy in the patient prognosis. }\end{array}$ \\
\hline $\begin{array}{l}\text { Average time for repairing faulty and malfunction information and communication } \\
\text { technology (ICT) equipment. }\end{array}$ & Making all the ICT functional is a way to enhance the efficiency of the health personnel in all areas. \\
\hline Average time taken to observe quality measure during and after a medical procedure. & $\begin{array}{l}\text { Good sanitation to rid tools of spills and contaminates before, during, and after a procedure and } \\
\text { proper detailing of all tools are key ways of ensuring quality of service. }\end{array}$ \\
\hline Challenge & Rationale \\
\hline $\begin{array}{l}\text { Average time taken in extracting facts about the prognosis of an outpatient in an } \\
\text { emergency situation. }\end{array}$ & $\begin{array}{l}\text { Most of the time, patient relatives are usually in distress and despair about a case to an extent of } \\
\text { withholding adequate information needed to commence treatment. }\end{array}$ \\
\hline $\begin{array}{l}\text { Average emergency time required to invite a specialist to attend to patients in a special } \\
\text { case and time required to refer to another health facility. }\end{array}$ & $\begin{array}{l}\text { The hospital does not have specialists for some classified treatments. Specialists might be engaged } \\
\text { or indisposed or reluctant. Most times, other health facilities are occupied, so patients have to queue } \\
\text { up. }\end{array}$ \\
\hline Average time taken to profile a new patient. & Inability to profile a patient on time could lead to the delay in discharging the treatment. \\
\hline Average time to take the vital signs of an out-patient. & Out-patients most times do not present themselves for monitoring of vital signs. \\
\hline Average time for admission and discharge. & $\begin{array}{l}\text { Lack of will and financial resources on the part of the patients could influence the admission and } \\
\text { discharge times. }\end{array}$ \\
\hline
\end{tabular}

Source: [Authors].

Table 3. Identified Environmental indicators and rationales for the Triple Bottom Line (TBL) of the Iranian General hospital determined according to Specific,

Measurable, Assignable, Realistic and Time-based (SMART) logic.

\begin{tabular}{cl}
\multicolumn{1}{c}{ Sustainability Criteria } & \multicolumn{1}{c}{ Environmental Sustainability } \\
\cline { 1 - 2 } Capacity & $\begin{array}{l}\text { Some patients could deliberately delay purchasing of their treatment essentials while waiting for } \\
\text { Government interventions. } \\
\text { Hazardous wastes have high impact on the environment and total wellbeing. } \\
\text { Constant and timely portable water is necessary for enhancing the general well-being of the patients } \\
\text { and for other sundry activities in the hospital. }\end{array}$ \\
$\begin{array}{l}\text { Average time for collecting and disposing of hazardous wastes. } \\
\text { Timely supply of portable water to the hospital facility and the patients. }\end{array}$ & \\
\hline
\end{tabular}


Table 3. Cont

\section{Challenge}

Timely response for repairs of all faulty electrical gadgets.

Ambulance is capable to bring patient on referral to and fro the health facility within 10 minutes.

Average time required between switching on alternative power supply whenever there is a power outage.

Average time taken between order and supply of consumables such as cotton wool, spirit, disinfectants, etc.

Average time required to outsource for bed spaces and bedding materials during an outbreak of diseases.

Average time for maintenance of all alternative power sources.

Limited time for producing and delivery hot water to patients.

\section{Rationale}

Functional gadgets are required for effective discharge of duties.

Ambulance services is most useful in the movement of patient to and fro their home to the hospital and also from the hospital to any referral center.

Switching on the alternative power source whenever there is an outage is important for continuous operation and could prevent pausing a procedure unduly.

ospital management especially in terms of contract for supplies most time are prone to strict administrative bureaucracy which usually delay the supply of the mentioned consumables. Getting adequate space and bedding materials to cope with high number of patients during emergency or during outbreak is usually a task for the hospital management.

Bureaucracy within the system could lead to delay of turn-around maintenance and the delivery of some services.

Cost of electricity and lack of alternative power source could lead to rationing of hot water to the wards for the use of the patients and other stakeholders.

Table 4. Identified Social indicators and rationales for the TBL of the Iranian General hospital determined according to SMART logic.

\begin{tabular}{c}
\hline Sustainability Criteria \\
\hline Social Sustainability \\
Capacity
\end{tabular}

\section{Capacity}

The hospital has the capacity to receive drugs and material supply from the supplier quarterly Average time for ward-round

Average time turn-around maintenance on the ceiling fan and air conditioners at the wards for the indoor air quality is conducted.

Timely and routine checks on all the security gadgets to ensure safety and security of the hospital.

Timely seminars, workshops and public enlightenment programs in

schools to sensitize the public about their health status.

Challenge

Average time between prescription by the doctor and dispensing of the drugs/materials at the pharmacy.

Average time taken for an in-patient to receive the prescribed drugs/material at the Pharmacy.

Average time taken for an out-patient to receive the prescribed drugs/material at the Pharmacy.

Average time required to place order and to receive supply of essential drugs for the continuation

of the patient's management.

Inadequate time of in-service courier officers to take consignments to and from various remote departments.

\section{Rationale}

Building confidence between suppliers and the hospital will enhance the relationship between them Adequate ward round session by the health practitioners will improve patient's confidence

Functional air conditioners and ceiling fans are necessary for comfort within the Hospital facility. Adequate security of people and properties is the most important confidence building measure between patients and patient relatives and the Hospital Management.

\section{Rationale}

Most patients' relatives prefer to purchase their medication outside the hospitals' pharmacy.

Long queue at the pharmacy could lead to delay in delivery of medications.

Queuing could be an issue that could lead to discomfort among patients.

The hospital does not stock some classified medications. Placing orders for them could lead to delay in treatment.

Some in-service courier officers could be aggressive in the way they address or attend to the patients' relatives. 


\section{Results and Discussion}

Exponential distribution validation results are presented in Tables 5-10. Figures 1-6 shows the position of the significant $\chi^{2}$ on the exponential distribution curve for each TBL. The $\chi^{2}$ obtained for all the indicators did not fall within the critical region, therefore we failed to reject $\mathrm{H}_{\mathrm{o}}$ and accepted that all the indicators are exponentially distributed. For the economic bottom line (Tables 5 and 6$), \chi^{2}: 16.9$ and 18.3 for both capacity and challenge, respectively, are less than the corresponding critical values: $\chi_{0.05,14}^{2}$ of 23.685 and $\chi_{0.05,16}^{2}$ of 26.296; these are outside the rejection region (Figures 1 and 2). We failed to reject $\mathrm{H}_{\mathrm{o}}$ and concluded that the distribution of the value of the capacity and challenge indicators for economic sustainability bottom line is exponentially distributed. Similarly, for the environmental bottom line, as shown in Tables 7 and $8, \chi^{2}: 12.1$ and 15.7 for both capacity and challenge, respectively, are less than their corresponding critical values: $\chi_{0.05,13}^{2}$ of 22.362 and $\chi_{0.05,16}^{2}$ of 26.296 . They are also outside the rejection region (See Figures 3 and 4); thus, we failed to reject $\mathrm{H}_{\mathrm{o}}$ and agreed that the distribution of value of the capacity and challenge indicators for the environmental sustainability bottom line are exponentially distributed. In a similar way, the social bottom line as presented in Tables 9 and 10, $\chi^{2}: 13.8$ and 14.3 for both capacity and challenge, respectively, are less than their corresponding critical values: $\chi_{0.05,12}^{2}$ of 21.026 and $\chi_{0.05,13}^{2}$ of 22.362 . Since the values fall outside the rejection region (See Figures 5 and 6), we equally failed to reject $H_{o}$ and concluded that the distribution of values of the capacity and challenge indicators for social sustainability bottom line are exponentially distributed. This validation can also be done through the $p$-values. The $p$-value is the smallest amount of probability indicating the rejection of Ho. Therefore, if $p$-value is greater than $\alpha(p$-value $>\alpha)$, then we shall fail to reject $\mathrm{H}_{\mathrm{o}}$. In this case study, the $p$-values of all the criteria and indicators are greater than $\alpha(p$-value $>\alpha)$, and we hereby conclude that all the indicators are exponentially distributed.

Table 5. Exponential distribution statistics of capacity factor for economic sustainability.

\begin{tabular}{|c|c|c|c|c|c|c|c|c|c|c|c|c|c|c|c|}
\hline Midpoint & 4,0 & 5,9 & 7,8 & 9,7 & 11,7 & 13,6 & 15,5 & 17,4 & 19,4 & 21,3 & 23,2 & 25,2 & 27,1 & 29,0 & 30,9 \\
\hline Lower & 3,0 & 4,9 & 6,9 & 8,8 & 10,7 & 12,6 & 14,6 & 16,5 & 18,4 & 20,3 & 22,3 & 24,2 & 26,1 & 28,0 & 30,0 \\
\hline Upper & 4,9 & 6,9 & 8,8 & 10,7 & 12,6 & 14,6 & 16,5 & 18,4 & 20,3 & 22,3 & 24,2 & 26,1 & 28,0 & 30,0 & 31,9 \\
\hline $\begin{array}{c}\text { Observed } \\
\text { frequency } o_{i}\end{array}$ & 76,0 & 59,0 & 32,0 & 19,0 & 20,0 & 8,0 & 4,0 & 6,0 & 5,0 & 3,0 & 3,0 & 1,0 & 2,0 & 0,0 & 1,0 \\
\hline $\begin{array}{c}\text { Expected } \\
\text { frequency } e_{i}\end{array}$ & 88,2 & 58,2 & 38,4 & 25,3 & 16,7 & 11,0 & 7,2 & 4,8 & 3,2 & 2,1 & 1,4 & 0,9 & 0,6 & 0,4 & 0,3 \\
\hline
\end{tabular}

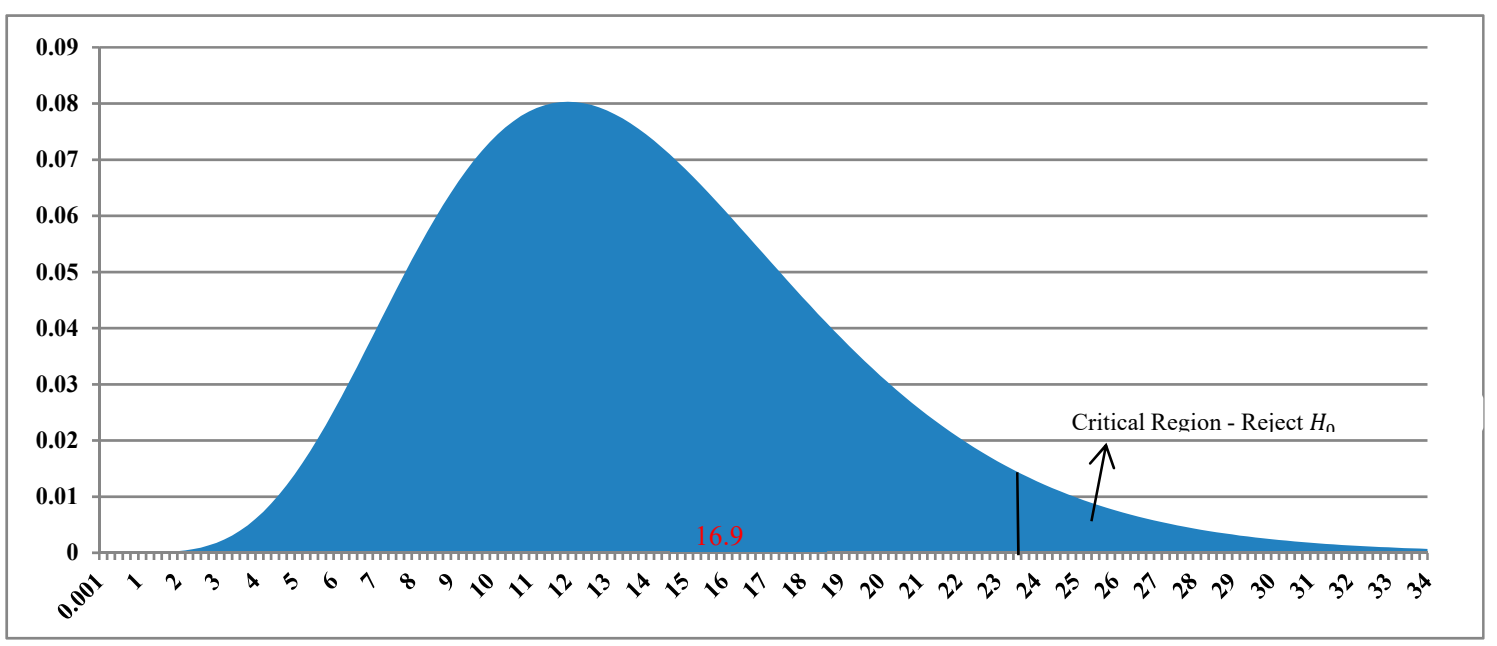

Figure 1. $\chi_{0.05,14}^{2}$ distribution curve of capacity factor for economic sustainability $(P$-value $=0.35)$. 
Table 6. Exponential distribution statistics of challenge factor for economic sustainability.

\begin{tabular}{|c|c|c|c|c|c|c|c|c|c|c|c|c|c|c|c|c|}
\hline Midpoint & 5,1 & 7,4 & 9,7 & 12,0 & 14,3 & 16,6 & 18,9 & 21,2 & 23,4 & 25,7 & 28,0 & 30,3 & 32,6 & 34,9 & 37,2 & 39,5 \\
\hline Lower & 4,0 & 6,3 & 8,6 & 10,9 & 13,2 & 15,4 & 17,7 & 20,0 & 22,3 & 24,6 & 26,9 & 29,2 & 31,5 & 33,7 & 36,0 & 38,3 \\
\hline Upper & 6,3 & 8,6 & 10,9 & 13,2 & 15,4 & 17,7 & 20,0 & 22,3 & 24,6 & 26,9 & 29,2 & 31,5 & 33,7 & 36,0 & 38,3 & 40,6 \\
\hline $\begin{array}{l}\text { Observed } \\
\text { frequency } o_{i}\end{array}$ & 62,0 & 64,0 & 34,0 & 25,0 & 15,0 & 13,0 & 8,0 & 1,0 & 2,0 & 4,0 & 2,0 & 1,0 & 1,0 & 0,0 & 1,0 & 1,0 \\
\hline $\begin{array}{l}\text { Expected } \\
\text { frequency } e_{i}\end{array}$ & 77,5 & 51,8 & 34,7 & 23,2 & 15,5 & 10,4 & 6,9 & 4,6 & 3,1 & 2,1 & 1,4 & 0,9 & 0,6 & 0,4 & 0,3 & 0,2 \\
\hline
\end{tabular}

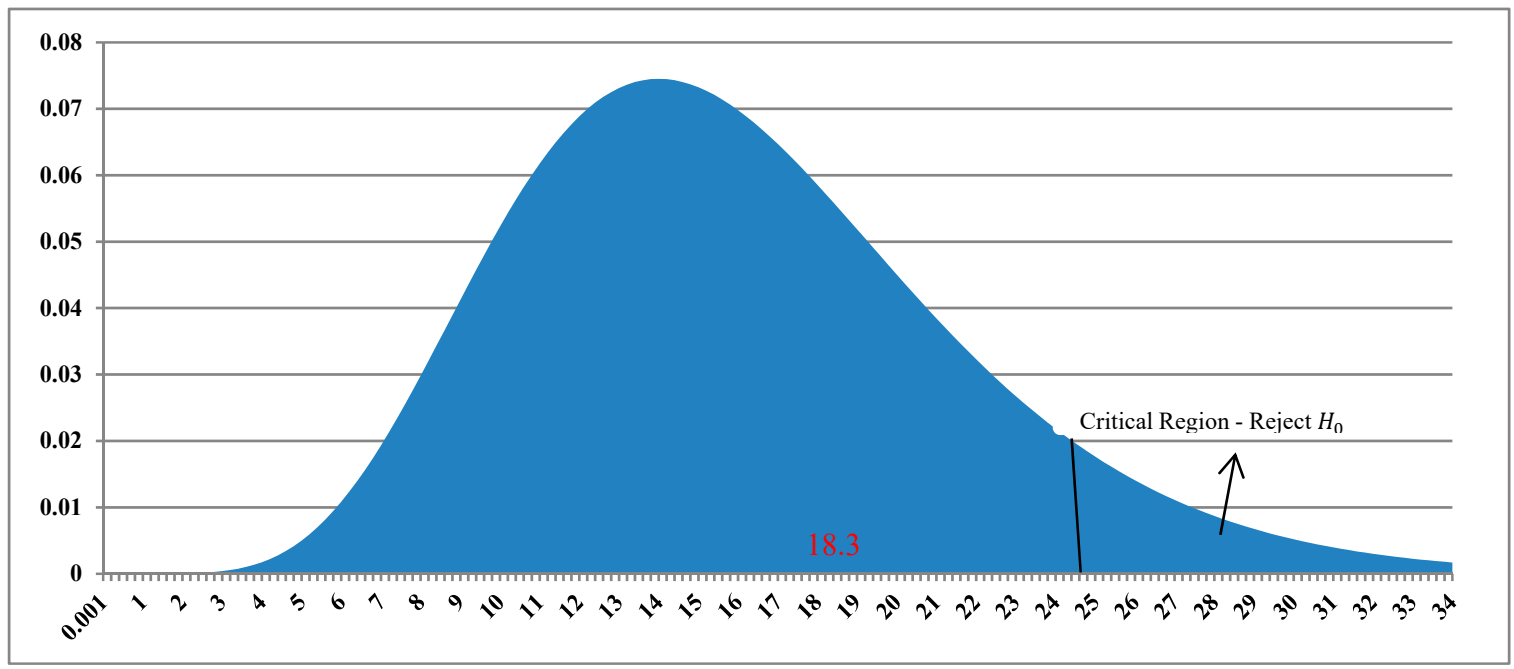

Figure 2. $\chi_{0.05,15}^{2}$ distribution curve of challenge factor for economic sustainability $(P$-value $=0.33)$.

Table 7. Exponential distribution statistics of capacity factor for environmental sustainability.

\begin{tabular}{lcccccccccccccc}
\hline Midpoint & $\mathbf{7 , 0}$ & $\mathbf{8 , 9}$ & $\mathbf{1 0 , 9}$ & $\mathbf{1 2 , 8}$ & $\mathbf{1 4 , 7}$ & $\mathbf{1 6 , 7}$ & $\mathbf{1 8 , 6}$ & $\mathbf{2 0 , 6}$ & $\mathbf{2 2 , 5}$ & $\mathbf{2 4 , 4}$ & $\mathbf{2 6 , 4}$ & $\mathbf{2 8 , 3}$ & $\mathbf{3 0 , 3}$ & $\mathbf{3 2 , 2}$ \\
Lower & 6,0 & 7,9 & 9,9 & 11,8 & 13,8 & 15,7 & 17,6 & 19,6 & 21,5 & 23,5 & 25,4 & 27,4 & 29,3 & 31,2 \\
Upper & 7,9 & 9,9 & 11,8 & 13,8 & 15,7 & 17,6 & 19,6 & 21,5 & 23,5 & 25,4 & 27,4 & 29,3 & 31,2 & 33,2 \\
$\begin{array}{l}\text { Observed } \\
\text { frequency } \boldsymbol{o}_{\boldsymbol{i}}\end{array}$ & 51,0 & 47,0 & 22,0 & 27,0 & 20,0 & 9,0 & 9,0 & 4,0 & 5,0 & 5,0 & 2,0 & 3,0 & 1,0 & 3,0 \\
$\begin{array}{l}\text { Expected } \\
\text { frequency } \boldsymbol{e}_{\boldsymbol{i}}\end{array}$ & 47,6 & 36,7 & 28,3 & 21,8 & 16,8 & 13,0 & 10,0 & 7,7 & 6,0 & 4,6 & 3,5 & 2,7 & 2,1 & 1,6 \\
\hline & \\
$\lambda_{1}=\frac{1}{11.7}, \chi^{2}$ statistics & $=\sum_{i=1}^{k} \frac{\left(o_{i}-e_{i}\right)^{2}}{e_{i}}=12.1$ and Critical $\chi_{\alpha, k-1}^{2}=\chi_{0.05,13}^{2}=22.362$ \\
\hline
\end{tabular}

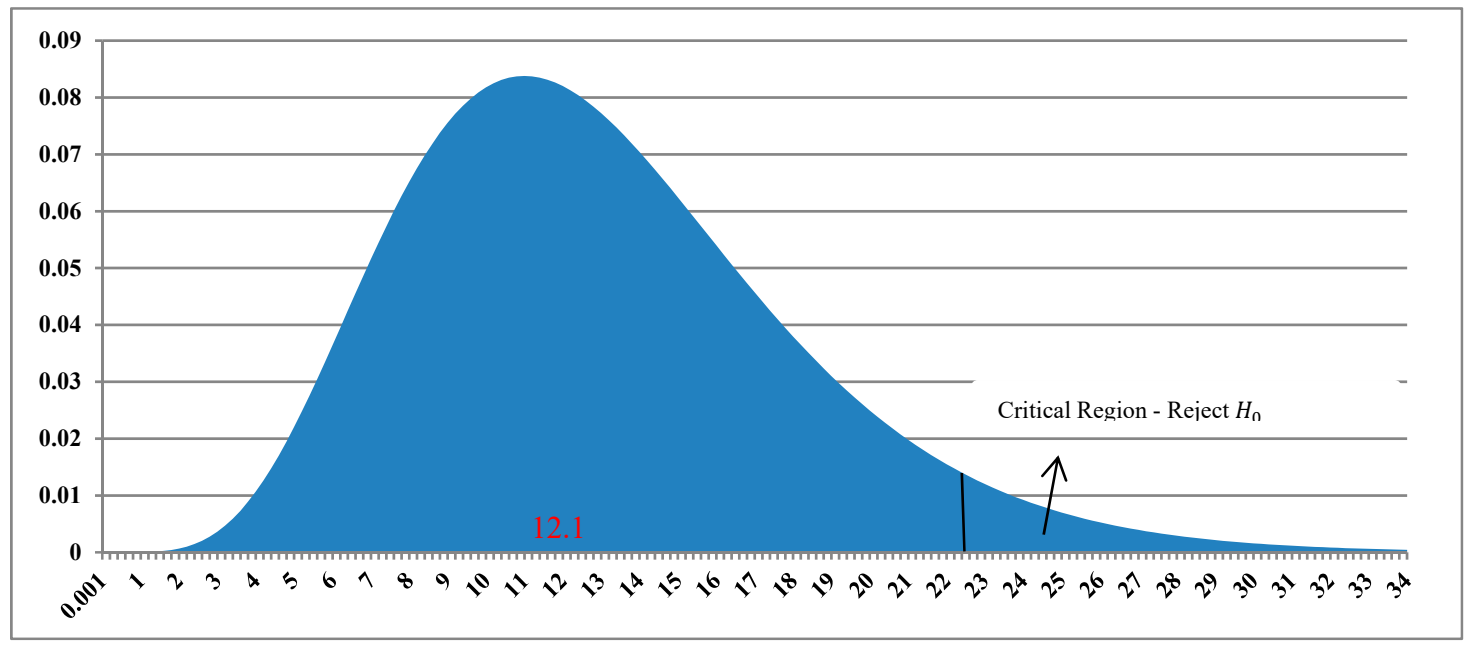

Figure 3. $\chi_{0.05,13}^{2}$ distribution curve of capacity factor for Environmental sustainability $(P$-value $=0.58)$. 
Table 8. Exponential distribution statistics of challenge factor for environmental sustainability.

\begin{tabular}{|c|c|c|c|c|c|c|c|c|c|c|c|c|c|c|c|c|c|}
\hline Midpoint & 5,6 & 6,8 & 8,1 & 9,3 & 10,5 & 11,7 & 13,0 & 14,2 & 15,4 & 16,7 & 17,9 & 19,1 & 20,3 & 21,6 & 22,8 & 24,0 & 25,2 \\
\hline Lower & 5,0 & 6,2 & 7,5 & 8,7 & 9,9 & 11,1 & 12,4 & 13,6 & 14,8 & 16,0 & 17,3 & 18,5 & 19,7 & 20,9 & 22,2 & 23,4 & 24,6 \\
\hline Upper & 6,2 & 7,5 & 8,7 & 9,9 & 11,1 & 12,4 & 13,6 & 14,8 & 16,0 & 17,3 & 18,5 & 19,7 & 20,9 & 22,2 & 23,4 & 24,6 & 25,8 \\
\hline $\begin{array}{l}\text { Observed } \\
\text { frequency } o_{i}\end{array}$ & 60,0 & 41,0 & 25,0 & 17,0 & 27,0 & 15,0 & 12,0 & 8,0 & 11,0 & 2,0 & 5,0 & 4,0 & 5,0 & 3,0 & 1,0 & 2,0 & 2,0 \\
\hline $\begin{array}{l}\text { Expected } \\
\text { frequency } e_{i}\end{array}$ & 50,6 & 40,0 & 31,5 & 24,9 & 19,6 & 15,5 & 12,2 & 9,6 & 7,6 & 6,0 & 4,7 & 3,7 & 2,9 & 2,3 & 1,8 & 1,4 & 1,1 \\
\hline
\end{tabular}

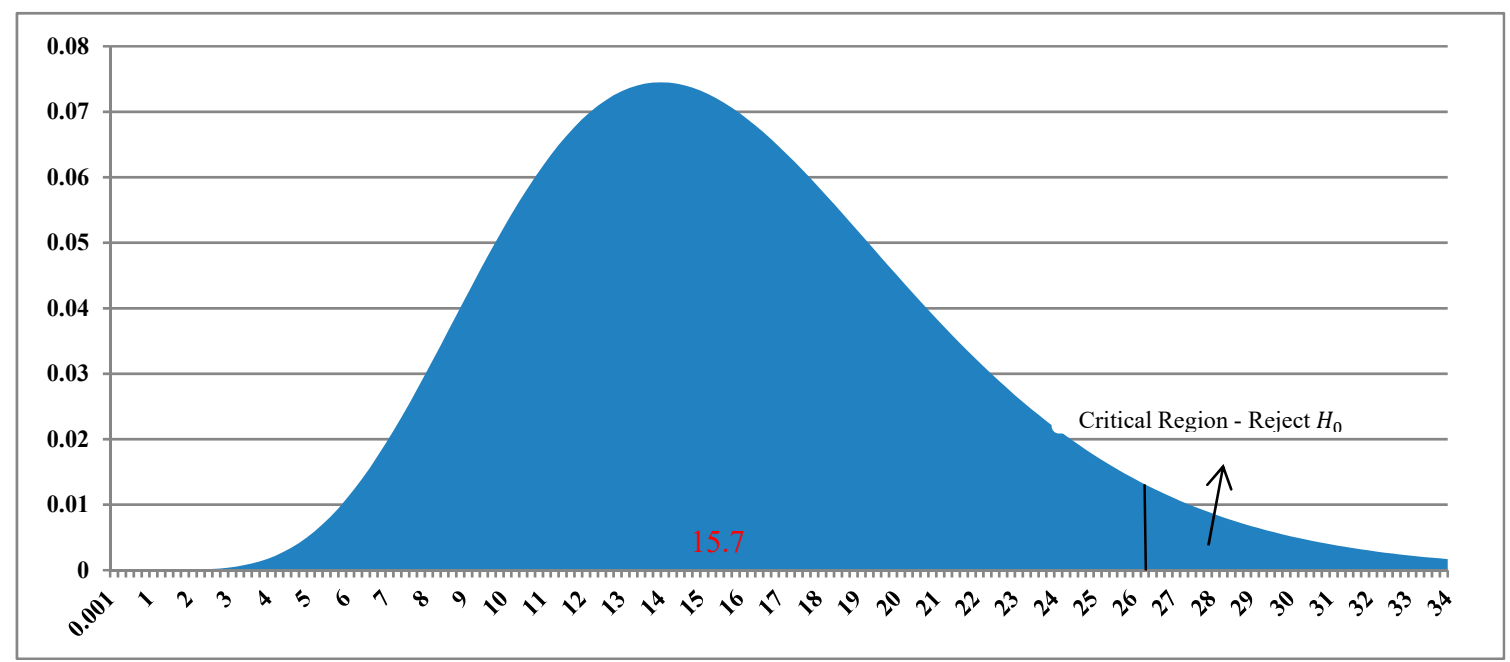

Figure 4. $\chi_{0.05,16}^{2}$ distribution curve of challenge indicator for Environmental sustainability $(P$-value $=0.54)$.

Table 9. Exponential distribution statistics of the capacity factor for social sustainability.

\begin{tabular}{lccccccccccccc}
\hline Midpoint & 9,3 & 11,9 & 14,4 & 17,0 & 19,6 & 22,1 & 24,7 & 27,3 & 29,8 & 32,4 & 35,0 & 37,6 & 40,1 \\
Lower & 8,0 & 10,6 & 13,1 & 15,7 & 18,3 & 20,9 & 23,4 & 26,0 & 28,6 & 31,1 & 33,7 & 36,3 & 38,8 \\
Upper & 10,6 & 13,1 & 15,7 & 18,3 & 20,9 & 23,4 & 26,0 & 28,6 & 31,1 & 33,7 & 36,3 & 38,8 & 41,4 \\
$\begin{array}{l}\text { Observed } \\
\text { frequency } o_{i}\end{array}$ & 42,0 & 35,0 & 21,0 & 19,0 & 9,0 & 6,0 & 9,0 & 5,0 & 3,0 & 2,0 & 1,0 & 1,0 & 2,0 \\
$\begin{array}{l}\text { Expected } \\
\text { frequency } e_{i}\end{array}$ & 32,5 & 25,7 & 20,3 & 16,0 & 12,7 & 10,0 & 7,9 & 6,3 & 4,9 & 3,9 & 3,1 & 2,4 & 1,9 \\
\hline & \\
$\lambda_{1}=\frac{1}{15.3}, \chi^{2}$ statistics $=\sum_{i=1}^{k} \frac{\left(o_{i}-e_{i}\right)^{2}}{e_{i}}=13.8$ and Critical $\chi_{\alpha, k-1}^{2}=\chi_{0.05,12}^{2}=21.026$ \\
\hline
\end{tabular}

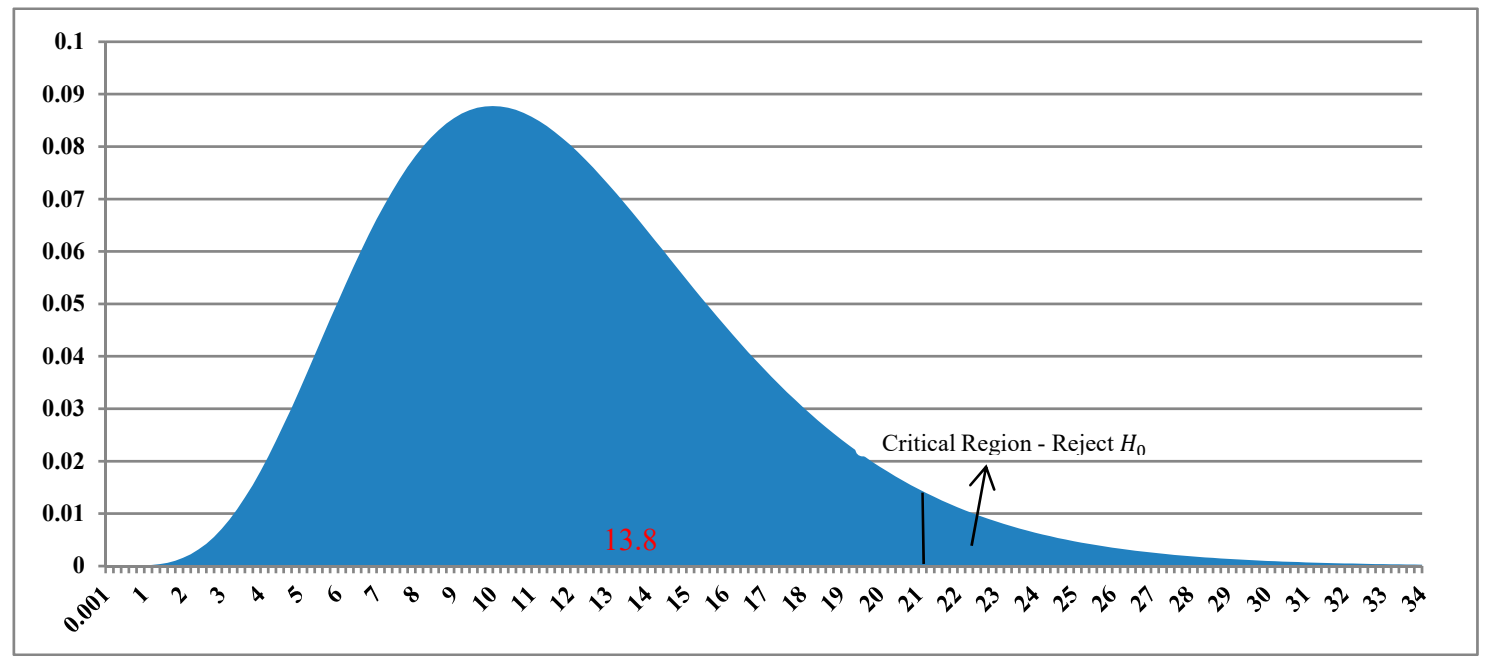

Figure 5. $\chi_{0.05,12}^{2}$ distribution curve of the capacity factor for Social sustainability $(P$-value $=0.41)$. 
Table 10. Exponential distribution statistics of the challenge factor for social sustainability.

\begin{tabular}{lcccccccccccccc}
\hline Midpoint & 3,2 & 5,7 & 8,1 & 10,5 & 13,0 & 15,4 & 17,9 & 20,3 & 22,8 & 25,2 & 27,6 & 30,1 & 32,5 & 35,0 \\
Lower & 2,0 & 4,4 & 6,9 & 9,3 & 11,8 & 14,2 & 16,7 & 19,1 & 21,5 & 24,0 & 26,4 & 28,9 & 31,3 & 33,7 \\
Upper & 4,4 & 6,9 & 9,3 & 11,8 & 14,2 & 16,7 & 19,1 & 21,5 & 24,0 & 26,4 & 28,9 & 31,3 & 33,7 & 36,2 \\
$\begin{array}{l}\text { Observed } \\
\text { frequency } o_{i}\end{array}$ & 99,0 & 52,0 & 31,0 & 31,0 & 12,0 & 10,0 & 8,0 & 4,0 & 2,0 & 3,0 & 0,0 & 1,0 & 1,0 & 1,0 \\
$\begin{array}{l}\text { Expected } \\
\text { frequency } e_{i}\end{array}$ & 96,3 & 59,9 & 37,3 & 23,2 & 14,4 & 9,0 & 5,6 & 3,5 & 2,2 & 1,3 & 0,8 & 0,5 & 0,3 & 0,2 \\
\hline & \\
$\lambda_{2}=\frac{1}{7.6}, \chi^{2}$ statistics $=\sum_{i=1}^{k} \frac{\left(o_{i}-e_{i}\right)^{2}}{e_{i}}=14.3$ and Critical $\chi_{\alpha, k-1}^{2}=\chi_{0.05,13}^{2}=22.362$ \\
\hline
\end{tabular}

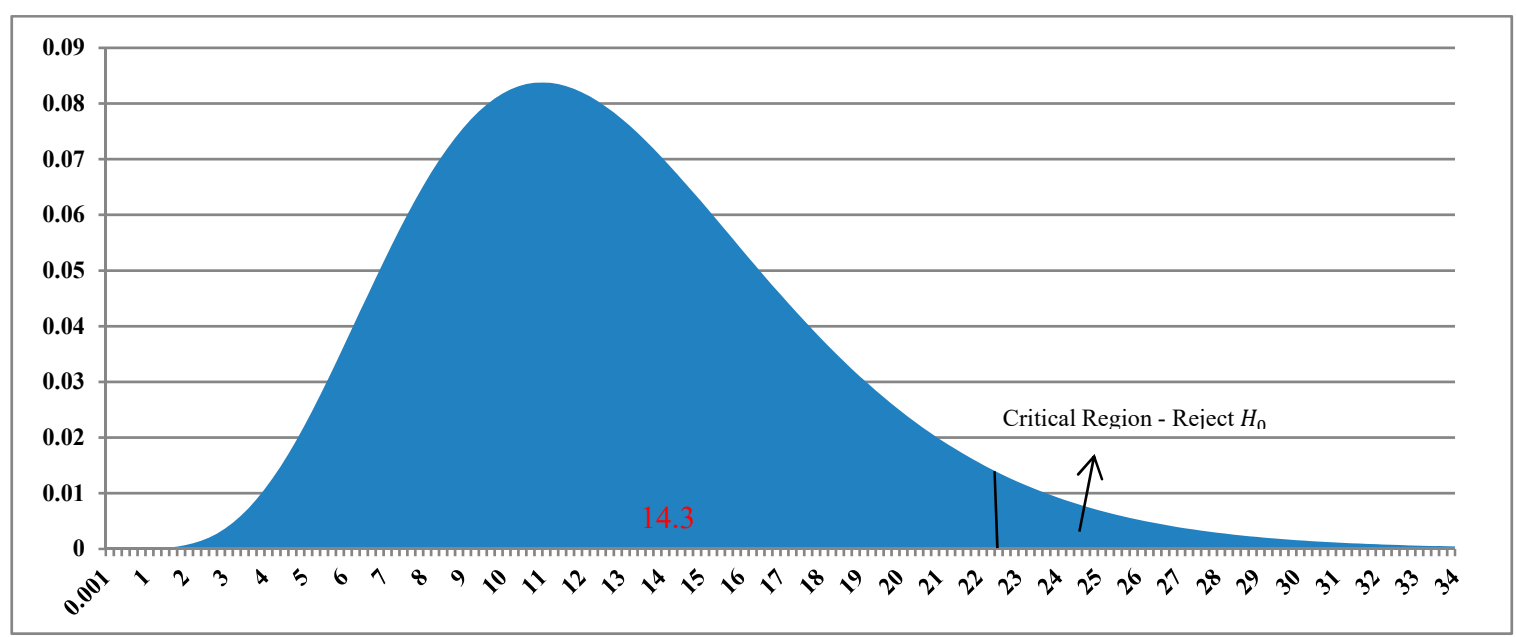

Figure 6. $\chi_{0.05,13}^{2}$ distribution curve of the challenge factor for Social sustainability $(P$-value $=0.44)$.

Utilizing the indicators in Tables $2-5$ and Equation (5), the sustainability of the hospital for one operating year (2016) was obtained according to Equation (8) as

$$
\text { Sustainability }=\int_{-\infty}^{0} \frac{\lambda_{1} \lambda_{2}}{\lambda_{1}+\lambda_{2}} \mathrm{e}^{\lambda_{2} \mathrm{y}} \mathrm{dy}
$$

For example,

$$
\text { social sustainability }=\int_{-\infty}^{0} \frac{\left(\frac{1}{15.3}\right) *\left(\frac{1}{7.6}\right)}{\left(\frac{1}{15.3}\right)+\left(\frac{1}{7.6}\right)} \mathrm{e}^{\frac{\mathrm{y}}{15.3}} \mathrm{dy}=0.668=66.80 \%
$$

Similarly, $54.40 \%$ and $48.80 \%$ are obtained for environmental and economic sustainability, respectively. This indicates that social sustainability of the hospital is the only macro-area that provided the most acceptable output. This could be as a result of the firm managerial know-how and good policy implementation. These must have been well managed and executed by all the stakeholders against all constraints imposed by the inadequacies of some of the indicators. More so, some other factors that have to do with the delivery, distribution of drugs, services, and some essential products also contributed to the average sustainability scores obtained. The outcome corroborates similar results [41-43]. Although the environmental sustainability index of $54.40 \%$ is abound the threshold, this is still unacceptable considering the critical nature of the healthcare system. The reason for this unsatisfactory result could be attributed to that fact that the hospital was not established with the aim of enhancing the environmental content of its operations. The concerns of the stakeholders as at the time of designing the hospital focused on rendering social and welfare needs and services to the citizen. Economic sustainability of $48.80 \%$ is considered low and unsatisfactory. This low output could be a result of the constraints imposed on the stakeholders in terms of the operational decision making. For instance, stakeholders are constrained within the limit of the current design of the environment 
and economic situations. For example, incessant power failure without an adequate alternative power source would reduce the public perception of the healthcare unit and also render the medical personnel redundant and ineffective. Also, lack of replacement of the faulty lighting bulbs or lights at some strategic places could reduce the public confidence. The inadequacies of the healthcare practitioners could be a result of malfunctioning essential equipment, poor environmental issues (poor office space, facility, etc.), and lack of adequate and state of the art equipment that could ease some operational services. Figure 7 revealed the magnitude of each of the TBL within the healthcare unit. For the healthcare to achieve adequate sustainability status, efforts should be made to improve the economic aspect of the hospital on a macro-scale.

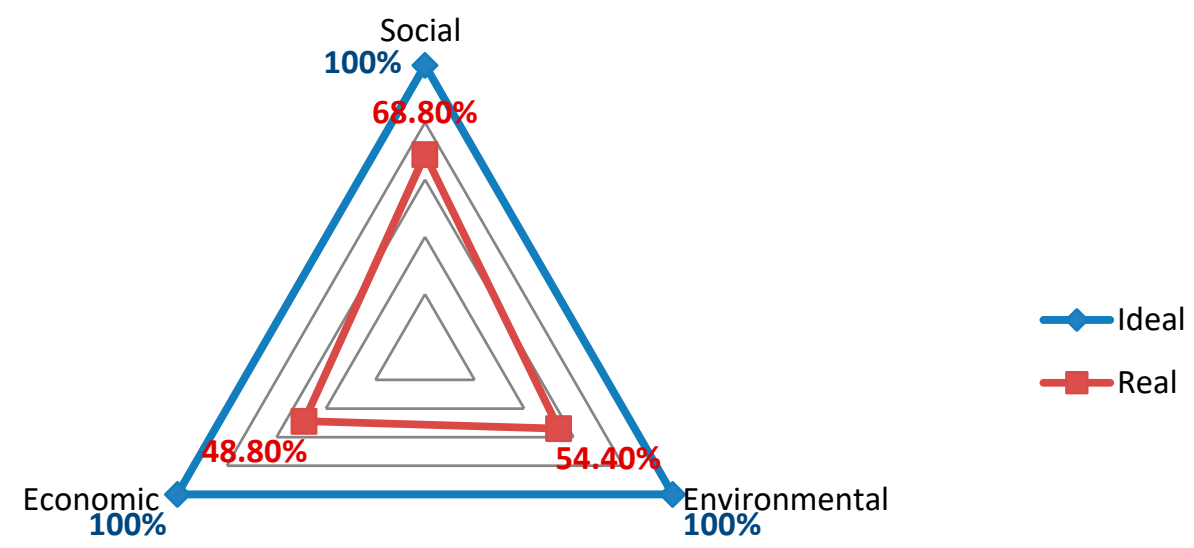

Figure 7. Radar plot of economic, environmental and social sustainability of the healthcare unit studied.

Generally, the healthcare unit can improve the sustainability score if efforts toward reducing the challenges or by increasing the capacity are intensified. Even just a slight change in any of these factors, as the case may be, could improve the score greatly, thereby enhancing the evaluation of all other possible strategies including a cost-benefit analysis.

\section{Conclusions}

The implementation of the concept of sustainability has been widely recognized to be cumbersome in real time. This includes difficulties experienced in measuring and monitoring the sustainability level of a healthcare system. For measuring empirically the sustainability of $n$ healthcare system, an exponentially distributed stochastic model is proposed in this study. In order to illustrate the effectiveness of the proposed model, a numerical case study of real data collated from an Iranian healthcare center is employed. The study, therefore, provides these contributions to the literature;

- A simple and specific statistical distribution validation framework for assessing and measuring sustainability. This study explicitly adopted an exponential distributed probabilistic approach to sustainability measurement.

- The proposed model could be used as a panoramic tool for measuring sustainability effectiveness in any other organizations with exponentially distributed indicators.

- Provided criteria and indicators are related and measured in the same unit, the proposed sustainability model would offer more opportunities and avenues for comparing the sustainability of different companies functioning in the same or related sectors.

For emphasis, the study did not address the impact of the environmental aspect of sustainability on the system or its surroundings, as advocated in other previously used models. Rather, it strongly recommends and emphasizes the need to always drive the measurement of sustainability index of healthcare with the actual statistical distribution of the sustainability indicators. However, since the study is premised on the positive and adequate perception of the users (patients and personnel) there 
is the need to further study how the indicated sustainability index would influence various business practices within the healthcare system. In another way, further works could be on the application of multivariate regression techniques to determine how each indicator contributes to variations in the sustainability index.

Author Contributions: All authors equally conceived and designed the experiment, and performed the experiment.

Funding: This research received no external funding.

Acknowledgments: The authors acknowledged Abigail Oluwakemi Adesina (RN), a Registered Nurse and her team, for vetting and streamlining the focus of the selected sustainability indicators used for the capacity and challenge factors. She has vast experience in the healthcare system.

Conflicts of Interest: The authors declare no conflict of interest.

\section{References}

1. WCED (World Commission on Environment and Development). Our Common Future; Oxford University Press: Oxford, UK, 1987.

2. Pulselli, F.M.; Ciampalini, F.; Tiezzi, E.; Zappia, C. The index of sustainable economic welfare (ISEW) for a local authority: A case study in Italy. Ecol. Econ. 2006, 60, 271-281. [CrossRef]

3. Distaso, A. Well-being and/or quality of life in EU countries through a multidimensional index of sustainability. Ecol. Econ. 2007, 64, 163-180. [CrossRef]

4. Floridi, M.; Pagni, S.; Falorni, S.; Luzzati, T. An exercise in composite indicators construction: Assessing the sustainability of Italian regions. Ecol. Econ. 2011, 70, 1440-1447. [CrossRef]

5. Salvati, L.; Carlucci, M. A composite index of sustainable development at the local scale: Italy as a case study. Ecol. Indic. 2014, 43, 162-171. [CrossRef]

6. Wagner, $\mathrm{M}$. The role of corporate sustainability performance for economic performance: A firm-level analysis of moderation effects. Ecol. Econ. 2010, 69, 1553-1560. [CrossRef]

7. Siche, J.R.; Agostinho, F.; Ortega, E.; Romeiro, A. Sustainability of nations by indices: Comparative study between environmental sustainability index, ecological footprint and the emergy performance indices. Ecol. Econ. 2008, 66, 628-637. [CrossRef]

8. Tom, K.; John, F. What is Sustainability? Sustainability 2010, 2, 3436-3448. [CrossRef]

9. Pearce, D.W.; Markandya, A.; Barbier, E.P. Blueprint for a Green Economy; Earthscan Publications: London, UK, 1989.

10. Daly, H.E. Forum-Georgescu-Roegen versus Solow/Stiglitz. Ecol. Econ. 1997, 22, 261-266. [CrossRef]

11. Ayres, R.U.; van den Bergh, J.C.J.M.; Gowdy, J.M. Viewopoint: Weak versus Strong Sustainability; Tinbergen Institute Discussion Papers; Tinbergen Institute: Amsterdam, The Netherland, 1998.

12. Elkington, J. Toward the Sustainable Corporation: Win-Win-Win Business Strategies for Sustainable Development. Calif. Manag. Rev. 1994, 36, 90-100. [CrossRef]

13. Liu, W.; Bai, E.; Liu, L.; Wei, W. A framework of sustainable service supply chain management: A literature review and research agenda. Sustainability 2017, 9, 421. [CrossRef]

14. Apte, S.; Sheth, J. Developing the Sustainable Edge. Lead. Lead. 2017, 2017, 48-53. [CrossRef]

15. Kim, D.; Kim, S. Sustainable supply chain based on news articles and sustainability reports: Text mining with Leximancer and DICTION. Sustainability 2017, 9, 1008. [CrossRef]

16. Pires, S.P.; Sénéchal, O.; Loures, E.F.R.; Jimenez, J.F. An approach to the prioritization of sustainable maintenance drivers in the TBL framework. IFAC-PapersOnLine 2016, 49, 150-155. [CrossRef]

17. Wirtenberg, J.; Russell, W.G.; Lipsky, D.; Enterprise Sustainability Action Team. The Sustainable Enterprise Fieldbook: When It All Comes Together; AMACOM: New York, NY, USA, 2009.

18. Tsasis, P.; Agrawal, N. An Embedded Systems Perspective in Conceptualizing Canada's Healthcare. Sustainability 2019, 11, 531. [CrossRef]

19. Lo Presti, L.; Testa, M.; Marino, V.; Singer, P. Engagement in Healthcare Systems: Adopting Digital Tools for a Sustainable Approach. Sustainability 2019, 11, 220. [CrossRef]

20. Chui, K.T.; Alhalabi, W.; Pang, S.S.H.; de Pablos, P.O.; Liu, R.W.; Zhao, M. Disease diagnosis in smart healthcare: Innovation, technologies and applications. Sustainability 2017, 9, 309. [CrossRef] 
21. Russell, D.A.M.; Shiang, D.L. Thinking about more sustainable products: Using an efficient tool for sustainability education, innovation, and project management to encourage sustainability thinking in a multinational corporation. ACS Sustain. Chem. Eng. 2013, 1, 2-7. [CrossRef]

22. Epstein, M.J.; Buhovac, A.R. Best Practices in Managing and Measuring Corporate Social, Enviornmental and Economic Impacts; Greenleaf Publishing Limited: Austin, TX, USA, 2014.

23. Savitz, A.W.; Weber, K. The Triple Bottom Line: How Today's Best-Run Companies Are Achieving Economic, Social, and Environmental Success-and How You Can Too; Jossey-Bass: San Francisco, CA, USA, 2006.

24. Ahi, P.; Searcy, C. A stochastic approach for sustainability analysis under the green economics paradigm. Stoch. Environ. Res. Risk Assess. 2013, 28, 1743-1753. [CrossRef]

25. Ekins, P.; Simon, S.; Deutsch, L.; Folke, C.; De Groot, R. A framework for the practical application of the concepts of critical natural capital and strong sustainability. Ecol. Econ. 2003, 44, 165-185. [CrossRef]

26. Capolongo, S.; Bottero, M.; Buffoli, M.; Lettieri, E. Improving Sustainability During Hospital Design and Operation; Springer: Cham, Switzerland, 2015.

27. Doran, G.T. There's a S.M.A.R.T. Way to Write Management's Goals and Objectives. Manag. Rev. 1981, 70, 35-36. [CrossRef]

28. Kondepudi, S.N.; Ramanarayanan, V.; Jain, A.; Singh, G.N.; Nitin Agarwal, N.K.; Kumar, R.; Singh, R.; Bergmark, P.; Hashitani, T.; Gemma, P.; et al. Smart Sustainable Cities: An Analysis of Definitions; International Telecommunication Union: Geneva, Switzerland, 2014.

29. Chi, Y.; Yu, C.; Qi, X.; Xu, H. Knowledge Management in Healthcare Sustainability: A Smart Healthy Diet Assistant in Traditional Chinese Medicine Culture. Sustainability 2018, 10, 4197. [CrossRef]

30. Norton, B.G.; Tom, M.A. Board of Regents of the University of Wisconsin System. Sustain. Ecol. Econ. Perspect. 2016, 73, 553-568.

31. Stern, D.I. The Capital Theory Approach to Sustainability: A Critical Appraisal. J. Econ. Issues 1997, 31, 145-174. [CrossRef]

32. Böhringer, C.; Jochem, P.E.P. Measuring the immeasurable-A survey of sustainability indices. Ecol. Econ. 2007, 63, 1-8. [CrossRef]

33. Bell, S.; Morse, S. Sustainability and Indicators: Measuring the Immeasureable; Routledge: London, UK, 2008.

34. US Green Building Council. LEED 2009 For Healthcare. 2016. Available online: http:/ /www.usgbc.org/ sites/default/files/LEED2009RS_HC_07.01.2016_clean.pdf (accessed on 1 March 2019).

35. BRE. Global Ltd. Bream Healthcare: Watford, NC, USA, 2010; Available online: https:/ /www.bregroup. com/about-us/bre-global/ (accessed on 1 March 2019).

36. United Nations Development Programmed (UNDP). Human Development Report 2003. Millennium Development Goals: A Compact among Nations to End Human Poverty; Oxford University Press for UNDP: New York, NY, USA, 2003.

37. JCI. Accreditation Standards for Hospitals; JCI: Oakbrook Terrace, IL, USA, 2011.

38. Heijungs, R.; Guinée, J.; Kleijn, R.; Rovers, V. LCA Methodology Bias in Normalization: Causes, Consequences. Detect. Remedies 2006, 2006, 1-6.

39. Bare, J.; Gloria, T.; Norris, G. Development of the method and U.S. normalization database for life cycle impact assessment and sustainability metrics. Environ. Sci. Technol. 2006, 40, 5108-5115. [CrossRef] [PubMed]

40. Walpole, R.E.; Myers, R.H.; Myers, S.L.; Ye, K. Probability \& Statistics for Engineers and Scientists, 9th ed.; Prentice Hall: Upper Saddle River, NJ, USA, 2011.

41. Buffoli, M.; Capolongo, S.; Bottero, M.; Cavagliato, E.; Speranza, S.; Volpatti, L. Sustainable Healthcare Sustainable Healthcare: How to assess and improve healthcare structures' sustainability. Ann Ig 2013, 25, 411-418. [CrossRef] [PubMed]

42. Buffoli, M.; Gola, M.; Rostagno, M.; Capolongo, S.; Nachiero, D. Making hospitals healthier: How to improve sustainability in healthcare facilities. Ann. Di Ig. Med. Prev. E Di Comunità 2014, 26, 418-425. [CrossRef]

43. Shannon, R.P. Eliminating hospital acquired infections: Is it possible? Is it sustainable? Is it worth it? Trans. Am. Clin. Climatol. Assoc. 2011, 122, 103-114. [PubMed]

(C) 2019 by the authors. Licensee MDPI, Basel, Switzerland. This article is an open access article distributed under the terms and conditions of the Creative Commons Attribution (CC BY) license (http:/ / creativecommons.org/licenses/by/4.0/). 